\title{
Treatment of gas-phase methanol in conventional biofilters packed with lava rock
}

Óscar J. Prado, María C. Veiga, Christian Kennes

Water Research,Volume 39, Issue 11, June 2005, Pages 2385-2393

DOI: $10.1016 /$ j.watres.2005.04.021

\begin{abstract}
The performance of laboratory scale methanol-degrading biofilters packed with lava rock was checked during almost $1 \mathrm{yr}$ under different conditions. The biomass concentration and biomass adaptation of the inoculum dramatically affected the start-up and the performance of the systems during the first stages of operation. A fast start-up was obtained when using concentrated and adapted inocula, while diluted or nonadapted inocula proved to be much less efficient. The performance of the reactor during long-term operation was significantly affected by the toxic load and moisture content of the gas. Critical loads between 120 and $280 \mathrm{~g} / \mathrm{m}^{3} \mathrm{~h}$ were reached during different phases of the study. The reactor had a high stability to EBRT changes when working at values between 48.0 and $91.1 \mathrm{~s}$, showing little or no negative effect when decreasing the EBRT. Hardly any difference was observed regarding performance when using either a downflow or upflow feed, although slightly better results were obtained when working in a downflow mode.
\end{abstract}

\section{Keywords}

Biofilter; EBRT; Lava rock; Methanol; Moisture; Nutrients

\section{Introduction}

During the recent past decades, the treatment of waste gases by means of biological technologies has proved to be an efficient and reliable alternative to traditional treatments based on physico-chemical principles. In bioreactors, the waste gas is put in contact with microorganisms, mainly bacteria and fungi, able to use the pollutant(s) as carbon and/or energy source. Commonly, biodegradation results in the generation of simple molecules with no or limited effect on human health or the environment, as water and carbon dioxide. Recently, the use of gas-phase bioreactors has increased widely, mainly due to their high efficiency and low costs. Nowadays, several different bioreactor types are available for specific applications in air pollution control (Kennes and Veiga, 2001). Research aimed at improving the operating strategy of these systems and increasing the reactor's performance and long-term stability have also been undertaken (Song and Kinney, 2001; Kennes and Veiga, 2002; Mendoza et al., 2003).

Methanol $\left(\mathrm{CH}_{3} \mathrm{OH}\right)$ is a volatile organic compound commonly used in industry, which may have harmful effects on human health. Therefore, it has been listed as one of the 
189 Hazardous Air Pollutants included in the 1990 Clean Air Amendment list in the US. Even though it may also have negative effects on microorganisms, different studies have proved that methanol can effectively be removed from air by means of bioreactors (Shareefdeen et al., 1993; Krailas et al., 2000; Dhamwichukorn et al., 2001; Kong et al., 2001; Cornabé et al., 2002; Prado et al., 2004). Methanol has been listed as a compound of "excellent biodegradability" (Zilli and Converti, 1999).

The present work describes several experiments that were performed in a series of conventional methanol-degrading biofilters packed with lava rock over a period of around 1 yr. The use of an inert material as filter bed allows a better gas distribution inside the reactor than organic carriers (Arulneyam and Swaminathan, 2000), although an initial inoculation with microorganisms is necessary as well as a periodical nutrient supply. The main objective of the work presented here was to check the performance of these systems under different situations that are commonly observed in industrial operation, as fluctuations in the emission rate or in the moisture content of the gas.

\section{Nomenclature}

\begin{tabular}{|c|c|}
\hline CC & Methanol concentration $\left(\mathrm{M} \mathrm{L}^{-3}\right)$ \\
\hline $\mathrm{C}_{\mathrm{inl}} \mathrm{Cinl}$ & Inlet Methanol concentration $\left(\mathrm{M} \mathrm{L}^{-3}\right)$ \\
\hline $\mathrm{C}_{6} \mathrm{C} 6$ & $\begin{array}{l}\text { Methanol concentration at } z=6 \mathrm{~cm} \mathrm{z}=6 \mathrm{~cm} \\
\left(\mathrm{M} \mathrm{L}^{-3}\right)\end{array}$ \\
\hline $\mathrm{C}_{25} \mathrm{C} 25$ & $\begin{array}{l}\text { Methanol concentration at } z=25 \mathrm{~cm} \\
\mathrm{z}=25 \mathrm{~cm}\left(\mathrm{M} \mathrm{L}^{-3}\right)\end{array}$ \\
\hline $\mathrm{C}_{44}=\mathrm{C}_{\text {out }} \mathrm{C} 44=$ Cout & $\begin{array}{l}\text { Methanol concentration at } z=44 \mathrm{~cm} \\
\mathrm{z}=44 \mathrm{~cm} \text { (outlet) }\left(\mathrm{M} \mathrm{L}^{-3}\right)\end{array}$ \\
\hline $\mathrm{CO}_{2 \text { inl }}$ & $\begin{array}{l}\text { Inlet carbon dioxide concentration } \\
\left(\mathrm{M} \mathrm{L}^{-3}\right)\end{array}$ \\
\hline $\mathrm{CO}_{\text {2out }}$ & $\begin{array}{l}\begin{array}{l}\text { Outlet carbon dioxide concentration } \\
\left(\mathrm{M} \mathrm{L}^{-3}\right)\end{array} \\
\end{array}$ \\
\hline EBRT & Empty bed residence time (t) \\
\hline EC & Methanol elimination capacity $\left(\mathrm{M} \mathrm{L}^{-3} \mathrm{t}^{-1}\right)$ \\
\hline $\mathrm{LL}$ & Methanol load (M L $\left.{ }^{-3} \mathrm{t}^{-1}\right)$ \\
\hline QQ & Gas flow rate $\left(\mathrm{L}^{3} \mathrm{t}^{-1}\right)$ \\
\hline $\mathrm{RE}$ & $\begin{array}{ll}\begin{array}{l}\text { Methanol removal } \\
\text { (dimensionless) }\end{array} & \\
\end{array}$ \\
\hline VV & Filter bed volume $\left(\mathrm{L}^{3}\right)$ \\
\hline VSS & Volatile suspended solids (M) \\
\hline $\mathrm{ZZ}$ & Distance from the reactor inlet (L) \\
\hline
\end{tabular}

\section{Materials and methods}

\subsection{Bioreactors}

Laboratory-scale conventional biofilters used throughout the study consisted in a glass cylinder packed with either 2.0 or $3.4 \mathrm{~L}$ lava rock. Filter bed characteristics have been described previously (Prado et al., 2004). Each reactor had four equidistant gas sampling ports at different heights. Most of the time the reactors were operated with a downward air flow, unless otherwise stated. The polluted gas fed to the biofilters was 
prepared by mixing two air streams. One of them passed through a bottle containing methanol (99.5\% purity, Panreac, Spain), while the second one passed through a water bath (Mendoza et al., 2003). All connections were made using Viton ${ }^{\mathrm{TM}}$ or silicone tubing. A general scheme of the systems can be found elsewhere (Prado et al., 2002), as well as the composition of the aqueous nutrient solution fed to the biofilters. During all the study the biofilters were kept at room temperature. All experiments were performed with a downward air flow except when studying the effect of that parameter on the reactor performance.

\subsection{Analytical methods}

Methanol concentration was measured by means of a HP-6890 gas chromatograph (Agilent T., Spain) equipped with a $30 \mathrm{~m} \times 0.53 \mathrm{~mm}$ HP-PLOT Q column and a flame ionization detector, operating in splitless mode. Oven temperature was $130{ }^{\circ} \mathrm{C}$, while both the injector and detector temperature was $150{ }^{\circ} \mathrm{C}$. Samples were injected using a $2.5 \mathrm{~cm}^{3}$ gas-tight Hamilton syringe. Under these conditions, the retention time of methanol was $3.5 \mathrm{~min}$. Calibrations were performed as described in the work of Prado et al. (2002). pH was measured by means of an Ingold U455-S7 electrode connected to a Crison pH-meter 507. A Warburg manometer was used to measure the pressure drop. Volatile suspended solids were determined according to Standard Methods ( APHA, 1989). A H270 temperature and relative humidity sensor (Dostmann E., Germany) was used to measure the relative humidity. $\mathrm{CO}_{2}$ concentrations were determined by means of a $\mathrm{CO}_{2}$-gas sensor (Vernier S. \& T., USA).

\subsection{Inoculum}

The biofilters were inoculated with fresh aerobic sludge obtained from the wastewater treatment plant of a synthetic resin-producing industry (Eiroa et al., 2004). The sludge was maintained for not more than 4-5 weeks in the laboratory at room temperature, with continuous supply of air, in order to minimize biomass decay and avoid anaerobic growth. After that time, unused sludge was replaced with new, fresh one. The characteristics of the sludge are given elsewhere (Prado et al., 2004).

\subsection{Performance parameters}

The following parameters were used to express the performance of the bioreactors (Kennes and Veiga, 2001):

$$
\begin{aligned}
& L(\text { Methanol load })=C_{\text {inl }} Q / V, \\
& \text { EC (methanol elimination capacity }) \\
& =\left(C_{\text {inl }}-C_{\text {out }}\right) Q / V, \\
& \operatorname{RE}(\text { methanol removal efficiency }) \\
& =\left(C_{\text {inl }}-C_{\text {out }}\right) 100 / C_{\text {inl } .} .
\end{aligned}
$$




\section{Results and discussion}

\subsection{Effect of the biomass concentration and biomass adaptation of the inoculum on start-up}

In a first study, conventional biofilters packed with $2.0 \mathrm{~L}$ lava rock were inoculated with four different inocula, in order to check the effect of the biomass concentration and biomass adaptation of the inoculum on the performance of the reactor during short-term operation. In the first three experiments, the sludge was diluted in distilled water in order to achieve biomass concentrations of, respectively, 3.5, 0.35 and $0.035 \mathrm{~g}$ VSS/L. The sludge had not been previously exposed to methanol. In the fourth experiment, the inoculation was performed with $0.35 \mathrm{~g} \mathrm{VSS} / \mathrm{L}$ adapted inoculum obtained from a methanol-degrading biofilter used in another study. According to Veiga and Kennes (2001), the use of an adapted inoculum may be an useful way to shorten the start-up time. Zilli et al. (1993), working with pure and mixed phenol-degrading batch cultures of Pseudomonas putida, proved that when the culture had been previously exposed to the toxic, the time needed for the microorganisms to fully degrade it was significantly shorter. Successive acclimations could reduce that time even to a higher extent. Both the inoculations and the operation of the reactors were carried out the same way in our four experiments. For the inoculations, the reactor was first filled with $1.6 \mathrm{~L}$ of sludge, which was drained off after $1 \mathrm{~h}$. Before the inoculation, $\mathrm{pH}$ of the sludge was set at 7.5, using diluted solutions of $\mathrm{NaOH}$ and $\mathrm{HCl}$. Immediately after the inoculum was drained off, the biofilter was supplied a constant methanol load of around $60 \mathrm{~g} / \mathrm{m}^{3} \mathrm{~h}$. During the four experiments the biofilter was operated with an EBRT of $48 \mathrm{~s}$ and a relative humidity above $90 \%$.

Fig. 1 shows the performance of the reactor in each experiment. Fourteen hours after the inoculation with the first sludge ( $3.5 \mathrm{~g} \mathrm{VSS} / \mathrm{L})$, the removal efficiency had reached values above 99\%. Such high efficiency was maintained for more than 1 week, with very high stability. Afterwards, the reactor was stopped and the filter bed replaced with new, clean lava rock for further experiments. A previous experiment performed with a non-inoculated reactor showed that no significant adsorption occurred on the support, proving that the elimination was due to the action of the microbes (data not shown). This proves that the sludge is highly adequate as inoculum for methanol degradation. 


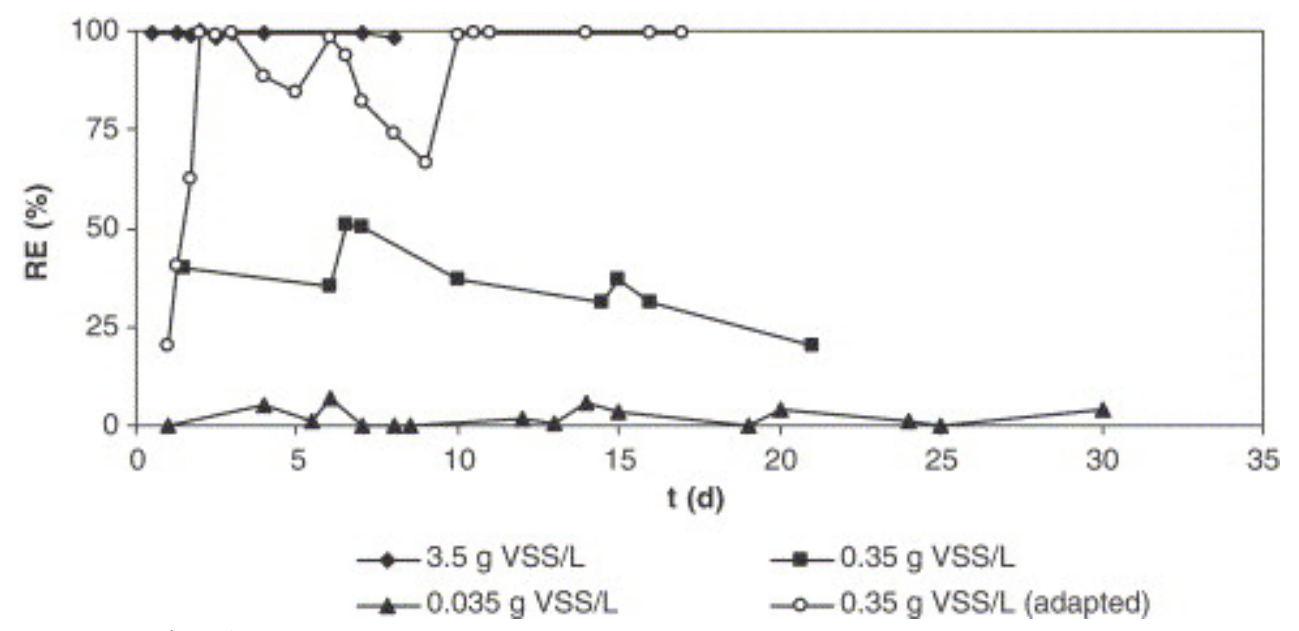

Fig. 1.

Influence of biomass concentration and biomass adaptation on the start-up of a biofilter fed a constant methanol load of $60 \mathrm{~g} / \mathrm{m}^{3} \mathrm{~h}$.

In the second case, when using $0.35 \mathrm{~g}$ VSS/L for inoculation, start-up was significantly slower (Fig. 1). The removal efficiency reached a highest value of around 50\%, 1 week after inoculation, decreasing later on to values below $25 \%$. The addition of $1.6 \mathrm{~L}$ nutrient solution on day 9 did not improve the reactor's performance. Indeed, the nutrient supply removed some biomass from the reactor, which may have had a negative effect on performance.

In the third experiment $0.035 \mathrm{~g}$ VSS/L was used for inoculation and only a low removal efficiency, always below 7\%, was observed even after 1 month of operation. As in the previous case, $1.6 \mathrm{~L}$ of nutrient solution was poured on top of the system after 9 days of operation, with no clear positive effect on performance. Although biomass detachment was not quantified during this experiment, it was observed in other studies that around $0.1 \mathrm{~kg} \mathrm{VSS} / \mathrm{m}^{3}$ packed bed can be removed on an average during nutrient supply (Kennes and Veiga, 2002; Mendoza et al., 2004), which is a low value but is highly significant in this work, compared to the $0.035 \mathrm{~g}$ VSS/L inoculated in the biofilter.

In the fourth experiment, with $0.35 \mathrm{~g}$ VSS/L of adapted sludge, the performance during the first 2 days of operation was similar as in the second experiment, in which a nonadapted sludge with the same biomass concentration had been inoculated. However, in this case the reactor's efficiency improved after that day, reaching an elimination efficiency of $100 \%$ on the third day of operation. This efficiency decreased after 4 days of operation, probably as a consequence of a lack of nutrients. As in the previous cases, 1.6 $\mathrm{L}$ of the nutrient solution was supplied on day 9. This resulted in a full recovery of the reactor's performance (Fig. 1).

These results prove that both the concentration of biomass in the inoculum and its adaptation to the pollutant may dramatically affect the performance and start-up of a biofilter packed with an inert filter bed. High biomass concentrations and an adaptation step of the inoculum reduce the start-up period and improve performance during the first stages of operation. Also, the results obtained in the fourth experiment show the convenience of assuring a good supply of moisture and nutrients during the start-up phase. This may be done through the periodical addition of a liquid nutrient solution. 
Inoculation with a too low biomass concentration and/or non-adapted sludge may lead to wash out problems and failure of the start-up procedure.

\subsection{Performance during long-term operation}

A conventional downflow biofilter packed with $3.4 \mathrm{~L}$ lava rock was started-up and operated during more than 7 months with a variable methanol load. Several other operation parameters were modified during this period, in order to check the behaviour of the reactor under different conditions. The inoculation of the reactor was performed in a similar way as in the first case of the previous experiment. The initial EBRT was $91 \mathrm{s.}$

During the first days of operation, with an inlet methanol load around $120 \mathrm{~g} / \mathrm{m}^{3} \mathrm{~h}$, removal efficiencies above $70 \%$ were achieved (Fig. 2). However, as in the previous study, the efficiency started soon to decrease as a consequence of a lack of nutrients. During the next days the inlet load was decreased. Also, on day 18 the biofilter was reinoculated with sludge obtained from a bioreactor employed for the treatment of a mixture of methanol and formaldehyde and fed $2 \mathrm{~L}$ nutrient solution. This led to an increase in the removal efficiency, that reached a stable value around $98 \%$ by day 26 of operation, when the methanol load was around $55 \mathrm{~g} / \mathrm{m}^{3} \mathrm{~h}$. From this day on, $2 \mathrm{~L}$ nutrient solution was fed weekly to the reactor. This addition is not only important as a nutrient supply, but also to compensate for water loss by evaporation.

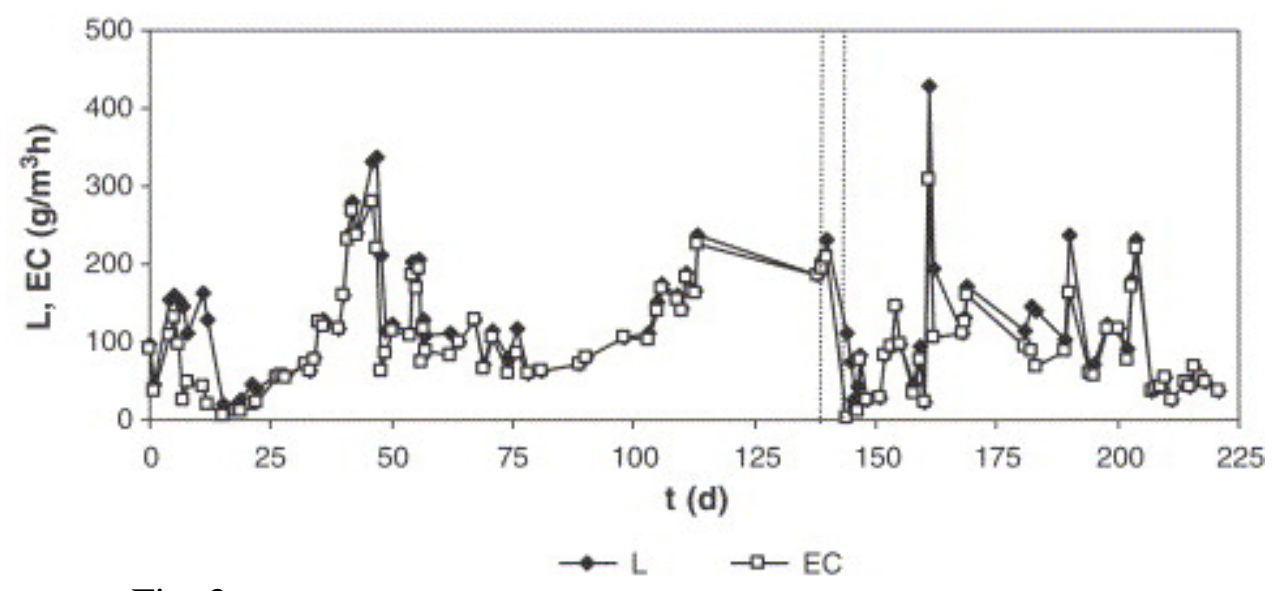

Fig. 2.

Reactor operation during the study. Area between the dotted lines shows the period of the humidification system failure.

Then, the methanol load was gradually increased up to values around $330 \mathrm{~g} / \mathrm{m}^{3} \mathrm{~h}$. As long as the inlet load remained below $280 \mathrm{~g} / \mathrm{m}^{3} \mathrm{~h}$, removal efficiencies close to $100 \%$ were reached (Fig. 2). Even though the elimination capacity was high during all the study, the pressure drop was negligible, reaching maximum values of only $4 \mathrm{~mm}$ water/m filter bed. This was partly due to the small weekly removal of biomass when feeding the liquid solution to the reactor. The $\mathrm{pH}$ of the biofilter was usually between 3 and 4 , as a consequence of the consumption of ammonium as nitrogen source by the microbes, with the release of protons in the medium and concomitant acidification. The critical load under these operating conditions was around $280 \mathrm{~g} / \mathrm{m}^{3} \mathrm{~h}$. As an example, Shareefdeen et al. (1993) obtained a maximum methanol elimination capacity of 
$112.8 \mathrm{~g} / \mathrm{m}^{3} \mathrm{~h}$ in a conventional biofilter packed with a mixture 2:3 (v:v) of peat and perlite. A value of $101 \mathrm{~g} / \mathrm{m}^{3} \mathrm{~h}$ was reached by Krailas et al. (2000) in two biofilters packed with a mixture of compost and pall rings (4:1, v:v). Cornabé et al. (2002) reached an elimination capacity as high as $175 \mathrm{~g} / \mathrm{m}^{3} \mathrm{~h}$ in a biofilter packed with porous ceramic Rashig rings that had been inoculated with a recombinant Pichia pastoris strain. Results similar to those obtained in the present study were achieved by Mohseni and Allen (2000), who reached a methanol elimination capacity of $250 \mathrm{~g} / \mathrm{m}^{3} \mathrm{~h}$ in two biofilters used for the treatment of a mixture of methanol and $\alpha$-pinene.

Subsequently, the supply of methanol loads as high as $330 \mathrm{~g} / \mathrm{m}^{3} \mathrm{~h}$ during $48 \mathrm{~h}$ (days 4647) resulted in a decrease in the removal efficiency (Fig. 2). Although the removal efficiency improved quickly after decreasing the inlet load, the critical load dropped to values between 120 and $180 \mathrm{~g} / \mathrm{m}^{3} \mathrm{~h}$ in the subsequent experiments.

Moisture content is another key parameter in bioreactor operation. Different studies published in the last years show that the relative humidity should be between $90 \%$ and $100 \%$ for optimal performance (van Lith et al., 1997; Jorio et al., 1998; Krailas et al., 2000; Kennes and Veiga, 2001; Estévez et al., 2005). Lower values will lead to drying out and channeling of the filter bed, decreasing the efficiency of the reactor. During our study, the biofilter was constantly fed air with a relative humidity value above $90 \%$. However, as a consequence of a failure in the humidification system between days 138 and 144, the bioreactor was fed air with a relative humidity below $1.0 \%$ during that period. As shown in Fig. 2, this led to a fast decrease in the efficiency of the biofilter. On day 144, the relative humidity of the inlet gas was restored to its initial value, leading to a quick recovery of the removal efficiency. In less that 1 week, values comparable to the ones obtained before the failure were reached.

\subsection{Study of methanol elimination at different reactor heights}

During the first 5 months after start-up, the methanol concentration was periodically checked at different heights of the reactor, at 0, 6, 25 and $44 \mathrm{~cm}$ from the inlet. Hence, three different zones of the reactor were studied separately: zone A (from the inlet to $z=6 \mathrm{~cm} \mathrm{z}=6 \mathrm{~cm})$, zone B $(6<z<25 \mathrm{~cm} 6<\mathrm{z}<25 \mathrm{~cm})$ and zone C $(25<z<44 \mathrm{~cm}$ $25<\mathrm{z}<44 \mathrm{~cm}$ ). The volume of each zone was, respectively, $0.46,1.47$ and $1.47 \mathrm{dm}^{3}$. Although the inlet concentration varied during the experiment, all the results shown in the present study were obtained under pseudo-stationary state with an inlet methanol concentration around $3.0 \mathrm{~g} / \mathrm{m}^{3}$. The methanol load was around $120 \mathrm{~g} / \mathrm{m}^{3} \mathrm{~h}$. In the first stages of the study most of the biodegradation took place in zone A (Fig. 3), even though its volume was only $13.5 \%$ of the filter bed. Meanwhile, zone $\mathrm{C}$ presented the lowest efficiency. This same pattern has been observed in different studies (Hodge et al., 1991; Arulneyam and Swaminathan, 2000; Cox et al., 2001; Lu et al., 2001; Prado et al., 2004), and may be due to the higher amount of carbon, water and nutrients that were available for the microorganisms in the inlet zone of the reactor ( $\mathrm{Lu}$ et al., 2001). However, after 10 weeks of operation, the relative contribution of zone A to the biodegradation had decreased, while it had increased in zone B. Although the local moisture content was not measured, it was considered that the decrease in the efficiency of zone A could be due to a lack of water near the inlet of the biofilter. Besides, observation of the filter bed showed that during the first 5 months of operation the concentration of biomass in zone B had gradually and significantly increased. However, zone $\mathrm{C}$ did not show a well-developed biofilm during the present study. 


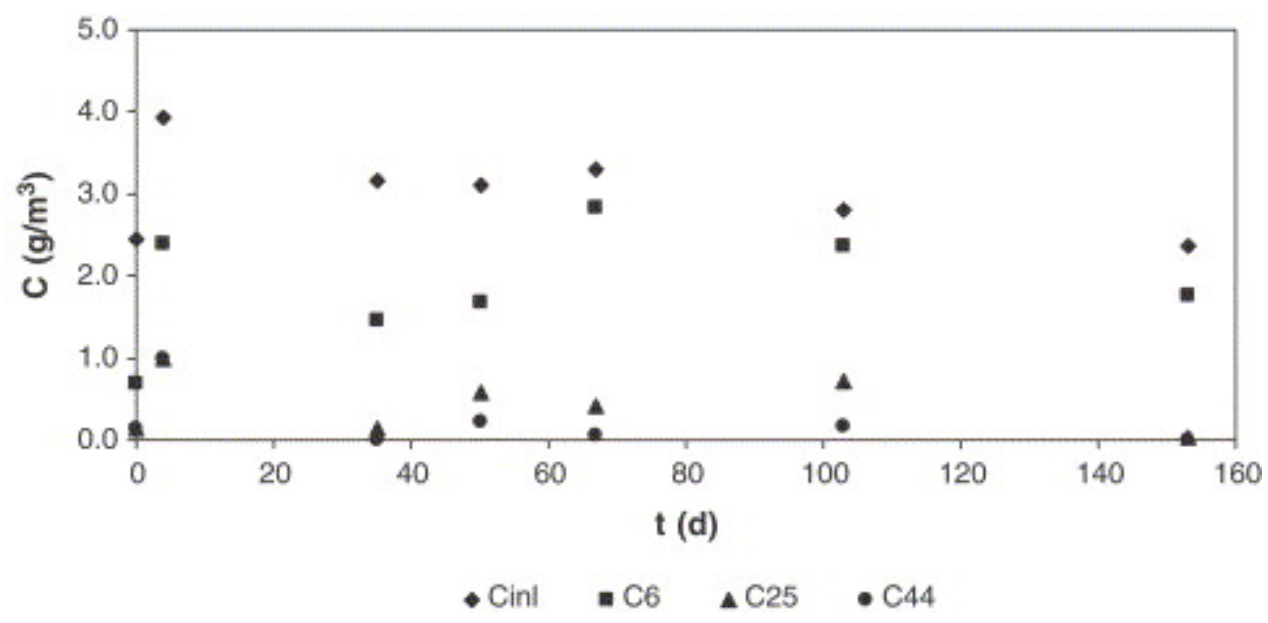

Fig. 3.

Methanol concentrations at different heights of the reactor, during the first 5 months of operation after start-up.

\subsection{Effect of highly variable EBRT on reactor performance (short-term study)}

In the present experiment, the stability of the system under conditions of highly variable EBRT was studied. The study was undertaken on day 104 of operation, when most of the degradation (around 75\%) took place in the middle zone of the biofilter (Fig. 3). Before the experiment was started, the reactor was operated at a constant EBRT of $91.1 \mathrm{~s}$ during 6 weeks. Then, the EBRT was decreased four times at intervals of 150 min each. EBRT changes were performed by modifying the gas flow rate. The EBRT used in the different stages were 91.1, 68.2, 62.0, 53.8 and $48.0 \mathrm{~s}$. The inlet methanol concentration was $2.6 \pm 0.2 \mathrm{~g} / \mathrm{m}^{3}$ throughout the study. Methanol concentration was measured at different heights of the biofilter in every stage. Results, presented in Table 1 and Fig. 4 and Fig. 5, show that the removal efficiency remained quite stable during the study, decreasing only slightly when the EBRT also did. The removal efficiency remained above $95 \%$ even at methanol loads of $180 \mathrm{~g} / \mathrm{m}^{3} \mathrm{~h}$ and a gas flow rate above $250 \mathrm{~L} / \mathrm{h}$. Although higher flow rates were not applied, it is expected that, at lower EBRT, the removal efficiency will decrease proportionally. The effect of the changes in EBRT on the degradation profile of the biofilter was also studied. Results (Table 1) show that the quick changes in EBRT did not have a significant effect on the degradation profile under these conditions. Only a small loss in the relative importance of the elimination in the middle zone of the reactor with respect to the lower zone could be observed when the EBRT decreased, but this was not really significant. 
Table 1.

Operation parameters and results obtained during each stage (average value \pm standard deviation)

\begin{tabular}{|l|l||l|l||l|l||}
\hline Stage & $\mathbf{1}$ & $\mathbf{2}$ & $\mathbf{3}$ & $\mathbf{4}$ & $\mathbf{5}$ \\
\hline$Q(\mathrm{~L} / \mathrm{h})$ & 134.3 & 179.5 & 197.4 & 227.6 & 255.1 \\
\hline \hline EBRT $(\mathrm{s})$ & 91.1 & 68.2 & 62.0 & 53.8 & 48.0 \\
\hline$C_{\text {inl }}\left(\mathrm{g} / \mathrm{m}^{3}\right)$ & $2.78 \pm 0.04$ & $2.56 \pm 0.09$ & $2.46 \pm 0.39$ & $2.85 \pm 0.03$ & $2.43 \pm 0.05$ \\
\hline$C_{6}\left(\mathrm{~g} / \mathrm{m}^{3}\right)$ & $2.54 \pm 0.22$ & $2.44 \pm 0.13$ & $2.34 \pm 0.32$ & $2.58 \pm 0.08$ & $2.33 \pm 0.08$ \\
\hline$C_{25}\left(\mathrm{~g} / \mathrm{m}^{3}\right)$ & $0.46 \pm 0.16$ & $0.57 \pm 0.04$ & $0.57 \pm 0.03$ & $0.60 \pm 0.05$ & $0.70 \pm 0.05$ \\
\hline$C_{44}\left(\mathrm{~g} / \mathrm{m}^{3}\right)$ & $0.03 \pm 0.04$ & $0.06 \pm 0.01$ & $0.06 \pm 0.01$ & $0.08 \pm 0.00$ & $0.12 \pm 0.04$ \\
\hline$L\left(\mathrm{~g} / \mathrm{m}^{3} \mathrm{~h}\right)$ & $109.8 \pm 1.6$ & $134.9 \pm 4.6$ & $142.8 \pm 22.8$ & $190.7 \pm 1.9$ & $182.1 \pm 3.6$ \\
\hline EC $\left(\mathrm{g} / \mathrm{m}^{3} \mathrm{~h}\right)$ & $108.4 \pm 0.2$ & $132.0 \pm 4.7$ & $139.4 \pm 23.2$ & $185.3 \pm 1.9$ & $173.1 \pm 3.6$ \\
\hline RE $(\%)$ & $98.8 \pm 1.6$ & $97.8 \pm 0.3$ & $97.6 \pm 0.6$ & $97.2 \pm 0.1$ & $95.1 \pm 1.5$ \\
\hline \hline
\end{tabular}

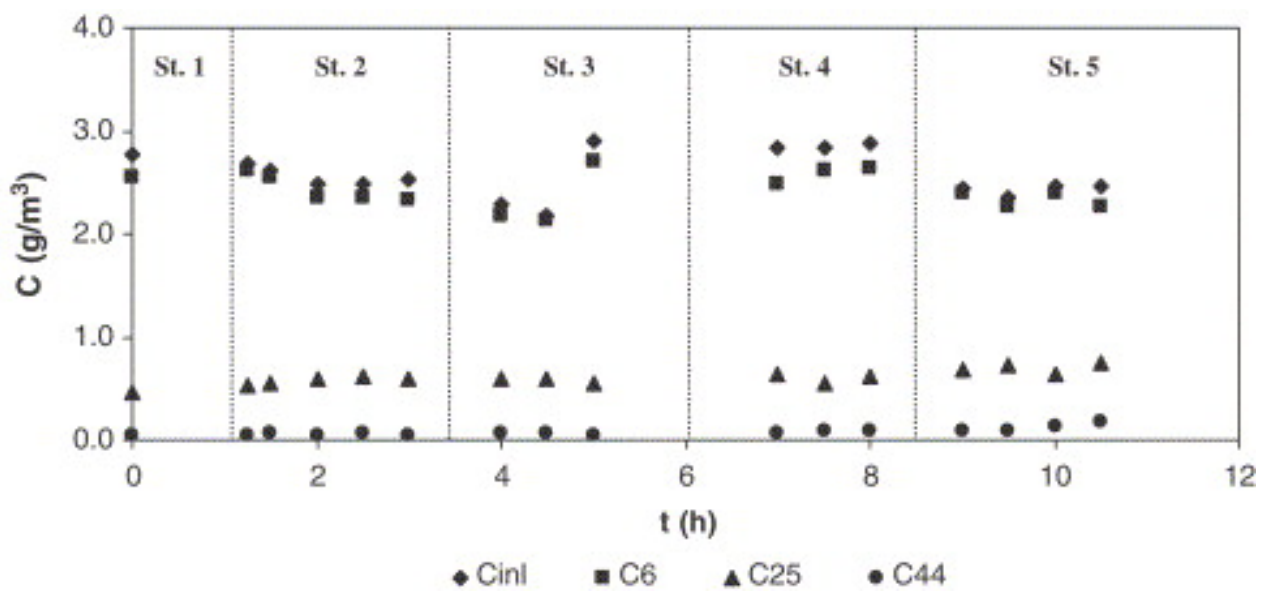

Fig. 4.

Methanol concentrations at different reactor heights during the experiment.

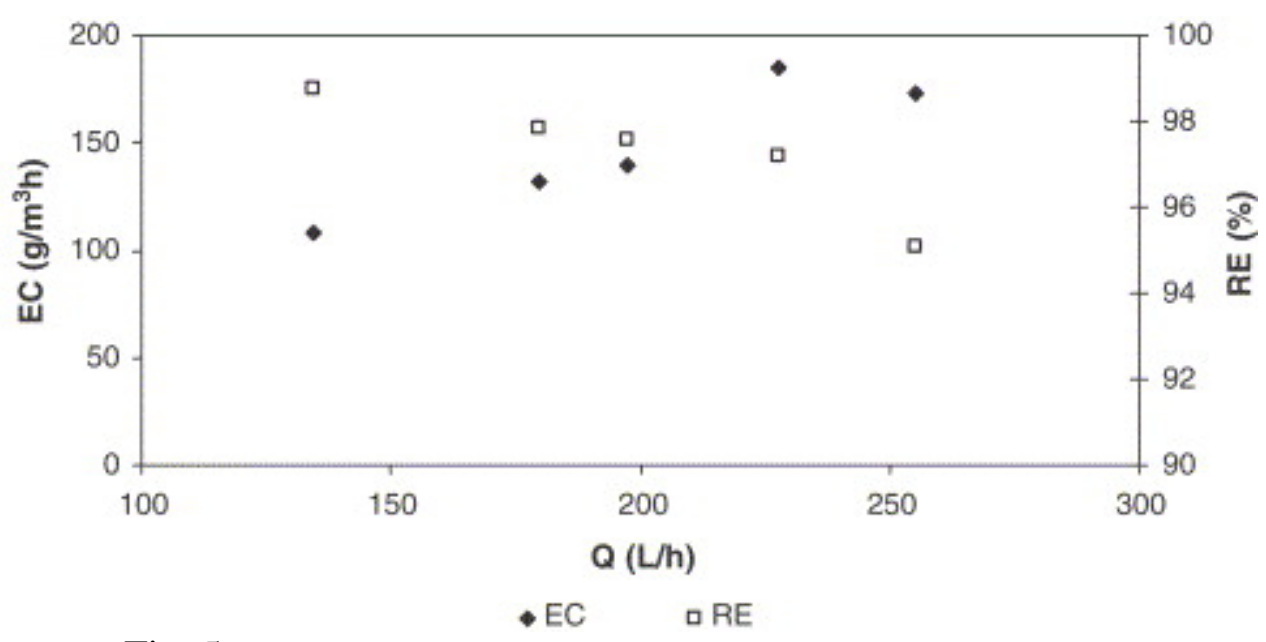

Fig. 5.

Effect of the gas flow rate on bioreactor performance. 
After this experiment, the reactor was operated during 5 weeks at the lowest EBRT of $48.0 \mathrm{~s}$ to check its stability over a longer period of time. During those 5 weeks, the methanol load was $180 \pm 28 \mathrm{~g} / \mathrm{m}^{3} \mathrm{~h}$, and the removal efficiency was $96.6 \pm 2.2 \%$. These results are consistent with the data presented in Table 1.

\subsection{Comparison of upflow and downflow operation}

Gas-phase bioreactors may be operated either in an upflow or a downflow mode. According to Devinny et al. (1999), downward air flow usually gives better results, as a consequence of the improvement of the moisture control. In a situation of drying out of the filter bed, which will generally appear first near the air inlet zone, the addition of water to the top of the carrier will easily solve the problem in a downward flow reactor. Such a treatment will not be so effective in an upward flow reactor, as drying out will start in the lower zone, less easily accessible. Another advantage is that downward operation allows better drainage.

The performance of our biofilter was studied under these two different operation modes, for more than 5 weeks each (Fig. 6 and Fig. 7). All the rest of the operation parameters were the same during all the experiment. In the first phase, the reactor was operated in a downflow mode with a methanol inlet load of $102.4 \pm 18.6 \mathrm{~g} / \mathrm{m}^{3} \mathrm{~h}$. A removal efficiency of $92.3 \pm 19.4 \%$ was obtained. Subsequently, the flow was switched to an upflow mode. Under these conditions, with an inlet load of $105.1 \pm 27.4 \mathrm{~g} / \mathrm{m}^{3} \mathrm{~h}$, a removal efficiency of $80.8 \pm 16.6 \%$ was achieved. These results show that the performance of the reactor was very similar in both cases (Fig. 7), although the average elimination capacity was slightly higher when operated in a downflow mode. After 6 weeks of operation in an upflow mode, downflow conditions were reestablished. Even though the inlet load was increased to an average of $120 \mathrm{~g} / \mathrm{m}^{3} \mathrm{~h}$, the removal efficiency increased to values above 97\%. Such a high elimination efficiency was maintained during more than 1 month without significant variations. This small improvement may be the result of a more homogeneous biomass distribution when switching from upflow to downflow operation (Song and Kinney, 2001; Kennes and Veiga, 2002). Krailas et al. (2000) also compared the performance of an upflow and a downflow methanol-degrading biofilter, observing that the elimination capacities were similar. However, they found that in the upward flow biofilter it was more difficult to compensate for water loss.

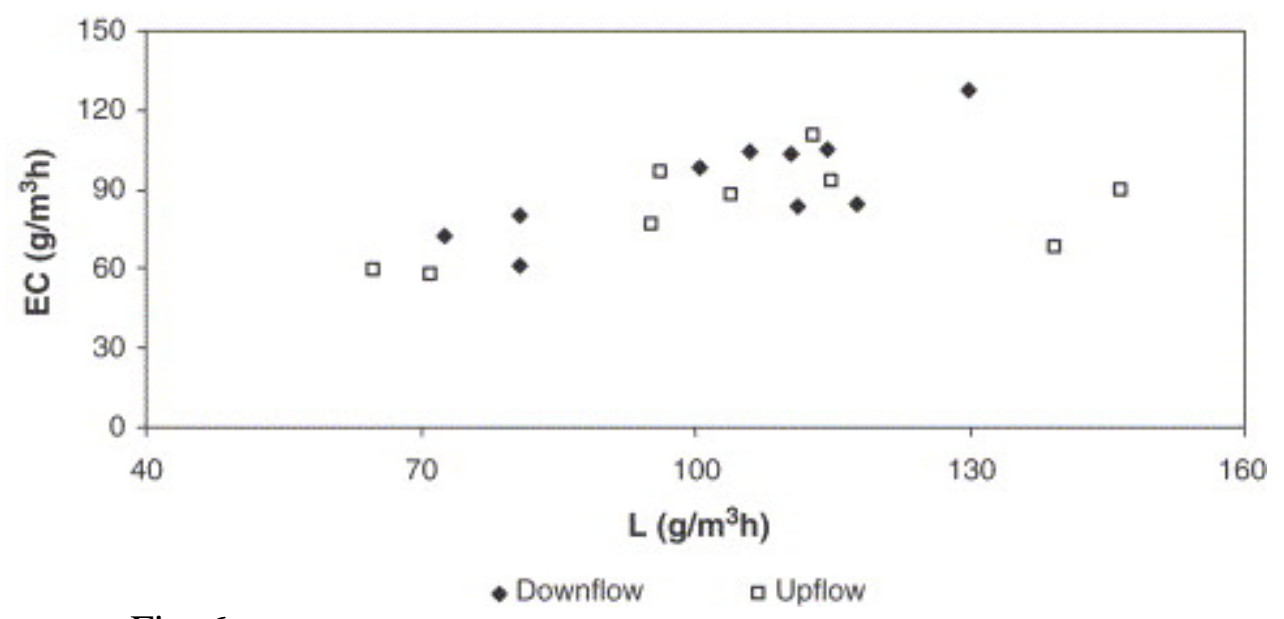

Fig. 6.

Effect of using an upflow or downward air flow on bioreactor performance. 




Fig. 7.

Performance of the bioreactor with upflow and downflow operation.

\subsection{Mineralization of methanol to $\mathrm{CO}_{2}$}

Ideally, if all the methanol supplied to the reactor is oxidized to carbon dioxide, the removal of $1 \mathrm{~g}$ of methanol will result in the production of $1.375 \mathrm{~g}$ of $\mathrm{CO}_{2}$, according to Eq. (1), neglecting biomass growth.

$\mathrm{CH}_{3} \mathrm{OH}+\frac{3}{2} \mathrm{O}_{2} \rightarrow 2 \mathrm{H}_{2} \mathrm{O}+\mathrm{CO}_{2}$.

However, conversion to carbon dioxide is not the only fate of the carbon source in a biofilter. Morales et al. (1998) found that $44.5 \%$ of the carbon was converted into $\mathrm{CO}_{2}$ in a toluene-degrading biofilter. Polymers and degradation intermediates represented $32.0 \%$, and the carbonates $14.3 \%$. The rest $(9.2 \%)$ was assumed to accumulate as biomass. Part of the carbon can also leave the reactor through the leachate, though this sink can usually be neglected in conventional biofilters since it does apparently represent less than 1\% of the carbon flux (Song and Kinney, 2000). Accordingly, carbon recoveries lower than $100 \%$ may be found if only $\mathrm{CO}_{2}$ production from biodegradation is considered. Nevertheless, other studies have shown that $\mathrm{CO}_{2}$ production may sometimes also exceed 100\% (Diks et al., 1994), which can be due to endogenous respiration and to respiration of biogenic material by secondary microbial populations.

In our biofilter, both inlet and outlet $\mathrm{CO}_{2}$ concentrations were measured from day 203 to day 222, with methanol loads ranging from 25.8 to $230.2 \mathrm{~g} / \mathrm{m}^{3} \mathrm{~h}$. The amount of methanol recovered as carbon dioxide was $57.6 \pm 11.4 \%$. These results are in the same range than others obtained by different authors (Kennes et al., 1996; Deshusses, 1997; Rihn et al., 1997; Cox et al., 1998; Woertz and Kinney, 2002; Estévez et al., 2005). A linear correlation was found between the concentration of methanol removed and $\mathrm{CO}_{2}$ production. Such a linear behaviour was also observed in a biofilter treating toluenepolluted air (Song and Kinney, 2000). 


\section{Conclusions}

The results shown in the present work prove that high loads of gas-phase methanol may be effectively treated by means of conventional biofilters packed with an inert carrier. The inoculation of a sludge obtained from the wastewater treatment plant of a formaldehyde-producing industry, in which low concentrations of methanol are sometimes present, can significantly shorten the start-up phase. Inoculating a high biomass concentration of adapted sludge will also speed-up and improve the performance of the start-up phase. In the present study, high elimination capacities were obtained, compared to the ones found in the literature for methanol. However, the supply of methanol loads above $300 \mathrm{~g} / \mathrm{m}^{3} \mathrm{~h}$ during more than 2 days caused a toxicity effect on the microbes, decreasing the removal efficiency. Critical loads between 120 and $280 \mathrm{~g} / \mathrm{m}^{3} \mathrm{~h}$ were achieved in the different phases of the study. The moisture content was found to be one of the critical parameters in the operation of the biofilters and the supply of dry air to the reactor during less than 1 week led to a fast decrease of its efficiency. However, a high performance could be quickly restored by supplying again air with a moisture content above $90 \%$. The system showed a high stability against changes in EBRT. The EBRT was decreased stepwise from an initial value of 91.1$48.0 \mathrm{~s}$, with little or no effect on the performance in the different stages of the experiment. There was hardly any difference between upflow and downflow operation, although slightly better results were obtained when working with a downward flow, probably as a consequence of the improvement in moisture and biomass distribution. Analysis of the carbon dioxide concentration at the inlet and at the outlet of the reactor showed that around $60 \%$ of the methanol fed to the biofilter was recovered as $\mathrm{CO}_{2}$.

\section{Acknowledgements}

The present research was funded by project PPQ 2001-0557. The doctoral research of ÓJP is financed by the Xunta de Galicia (Spain).

\section{References}

American Public Health Association (APHA)/American Water Works Association/Water Pollution Control Federation, 1989. In: Clesceri, L.S., Greenberg, A.E., Trussell, R.R. (Eds.). Standard Methods for the Examination of Water and Wastewater. 17th ed. Washington DC, USA

D. Arulneyam, T. Swaminathan

Biodegradation of ethanol vapour in a biofilter

Bioprocess Eng., 22 (2000), pp. 63-67

Cornabé, T., Auria, R., Christen, P., Ferrer, H., Revah, S., Moukha, S., 2002. Biofiltration of methanol by a recombinant Pichia pastoris strain. In: Proceedings of the 2002 USC-TRG Conference on Biofiltration. Newport Beach, California, USA, October 31-November 1. 
Cox, H.H.J., Nguyen, T.T., Deshusses, M.A., 1998. Elimination of toluene vapors in biotrickling filters: performance and carbon balances. In Proceedings Of The 91st Annual Meeting And Exhibition Of The Air And Waste Management Association. San Diego, California, USA, June 14-18.

H.H.J. Cox, T. Sexton, Z.M. Shareefdeen, M.A. Deshusses

Thermophilic biotrickling filtration of ethanol vapors

Environ. Sci. Technol., 35 (2001), pp. 2612-2619

M.A. Deshusses

Transient behavior of biofilters: start-up, carbon balances, and interaction between pollutants

J. Environ. Eng., 123 (1997), pp. 563-568

J.S. Devinny, M.A. Deshusses, T.S. Webster

Biofiltration for Air Pollution Control

CRC Lewis Publishers, Boca Raton, USA (1999)

S. Dhamwichukorn, G.T. Kleinheinz, S.T. Bagley

Thermophilic biofiltration of methanol and $\alpha$-pinene

J. Ind. Microbiol. Biotechnol., 26 (2001), pp. 127-133

R.M.M. Diks, S.P.P. Ottengraf, S. Vrijland

The existence of a biological equilibrium in a trickling filter for waste gas purification

Biotechnol. Bioeng., 44 (1994), pp. 1279-1287

M. Eiroa, C. Kennes, M.C. Veiga

Formaldehyde biodegradation and its inhibitory effect on nitrification

J. Chem. Technol. Biotechnol., 79 (2004), pp. 499-504

Estévez, E., Veiga, M.C., Kennes, C., 2005. Biofiltration of waste gases with the fungi Exophiala oligosperma and Paecilomyces variotii. Appl. Microbiol. Biotechnol. 67, in press, Doi:10.1007/s00253-004-1786-0.

D.S. Hodge, V.F. Medina, R.L. Islander, J.S. Devinny

Treatment of hydrocarbon fuel vapors in biofilters

Environ. Technol., 12 (1991), pp. 655-662

H. Jorio, K. Kiared, R. Brzezinski, A. Leroux, G. Viel, M. Heitz

Treatment of air polluted with high concentrations of toluene and xylene in a pilot-scale biofilter

J. Chem. Technol. Biotechnol., 73 (1998), pp. 183-196

C. Kennes, M.C. Veiga

Bioreactors for Waste Gas Treatment

Kluwer Academic Publishers, Dordrecht, The Netherlands (2001) 
C. Kennes, M.C. Veiga

Inert filter media for the biofiltration of waste gases-characteristics and biomass control

Re/Views Environ. Sci. Bio/Technol., 1 (2002), pp. 201-214

C. Kennes, H.H.J. Cox, H.J. Doddema, W. Harder

Design and performance of biofilters for the removal of alkylbenzene vapors

J. Chem. Technol. Biotechnol., 66 (1996), pp. 300-304

Z. Kong, L. Farhana, R.R. Fulthorpe, D.G. Allen

Treatment of volatile organic compounds in a biotrickling filter under thermophilic conditions

Environ. Sci. Technol., 35 (2001), pp. 4347-4352

S. Krailas, Q. Tuan Pham, R. Amal, J.K. Jiang, M. Heitz

Effect of inlet mass loading, water and total bacteria count on methanol elimination using upward flow and downward flow biofilters

J. Chem. Technol. Biotechnol., 75 (2000), pp. 299-305

C. Lu, M.R. Lin, I. Wey

Removal of pentane and styrene mixtures from waste gases by a trickle-bed air biofilter J. Chem. Technol. Biotechnol., 76 (2001), pp. 820-826

J.A. Mendoza, M.C. Veiga, C. Kennes

Biofiltration of waste gases in a reactor with a split-feed

J. Chem. Technol. Biotechnol., 78 (2003), pp. 703-708

J.A. Mendoza, Ó.J. Prado, M.C. Veiga, C. Kennes

Hydrodynamic behaviour and comparison of technologies for the removal of excess biomass in gas-phase biofilters

Water Res., 38 (2004), pp. 404-413

M. Mohseni, D.G. Allen

Biofiltration of mixtures of hydrophilic and hydrophobic volatile organic compounds

Chem. Eng. Sci., 55 (2000), pp. 1545-1558

W. Morales, S. Revah, R. Auria

Start-up and the effect of gaseous ammonia additions on a biofilter for the elimination of toluene vapors

Biotechnol. Bioeng., 60 (1998), pp. 483-491

Ó.J. Prado, J.A. Mendoza, M.C. Veiga, C. Kennes

Optimization of nutrient supply in a downflow gas-phase biofilter packed with an inert carrier

Appl. Microbiol. Biotechnol., 59 (2002), pp. 567-573

Ó.J. Prado, M.C. Veiga, C. Kennes

Biofiltration of waste gases containing a mixture of formaldehyde and methanol

Appl. Microbiol. Biotechnol., 65 (2004), pp. 235-242 
M.J. Rihn, X. Zhu, M.T. Suidan, B.J. Kim, B.R. Kim

The effect of nitrate on VOC removal in trickle-bed biofilters

Water Res., 31 (1997), pp. 2997-3008

Z. Shareefdeen, B.C. Baltzis, Y.S. Oh, R. Bartha

Biofiltration of methanol vapor

Biotechnol. Bioeng., 41 (1993), pp. 512-524

J.H. Song, K.A. Kinney

Effect of vapour-phase bioreactor operation on biomass accumulation, distribution, and activity: linking biofilm properties to bioreactor performance

Biotechnol. Bioeng., 68 (2000), pp. 508-516

J.H. Song, K.A. Kinney

Effect of directional switching frequency on toluene degradation in a vapor-phase bioreactor

Appl. Microbiol. Biotechnol., 56 (2001), pp. 108-113

C. van Lith, G. Leson, R. Michelsen

Evaluating desing options for biofilters

J. Air and Waste Manage. Assoc., 47 (1997), pp. 37-48

M.C. Veiga, C. Kennes

Parameters affecting performance and modeling of biofilters treating alkylbenzenepolluted air

Appl. Microbiol. Biotechnol., 55 (2001), pp. 254-258

Woertz, J.R., Kinney, K.A., 2002. Nitrogen effects on fungal culture growth and bioreactor performance. In: Proceedings of the 2002 USC-TRG Conference on Biofiltration. Newport Beach, California, USA, October 31-November 1.

M. Zilli, A. Converti

Biofilters

M.C. Flickinger, S.W. Drew (Eds.), Encyclopedia of bioprocess technology. Fermentation, biocatalysis and bioseparation, Wiley, New York, USA (1999), pp. 305381

M. Zilli, A. Converti, A. Lodi, M. del Borghi, G. Ferraiolo

Phenol removal from waste gases with a biological filter by Pseudomonas putida

Biotechnol. Bioeng., 41 (1993), pp. 693-699 